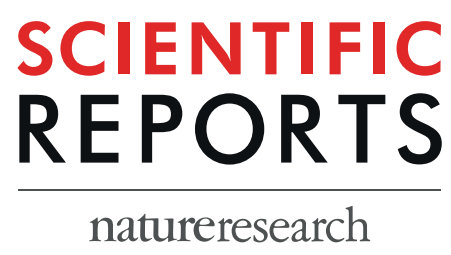

\title{
OPEN A new possible megalosauroid theropod from the Middle Jurassic Xintiangou Formation of Chongqing, People's Republic of China and its implication for early tetanuran evolution
}

\author{
Hui Dai ${ }^{1 *}$, Roger Benson ${ }^{2}$, Xufeng Hu${ }^{1}$, Qingyu $\mathrm{Ma}^{1}, \mathrm{Chao} \mathrm{Tan}^{1}$, Ning $\mathrm{Li}^{1}$, Ming Xiao ${ }^{1}$, \\ Haiqian $\mathrm{Hu}^{1}$, Yuxuan $\mathrm{Zhou}^{1}$, Zhaoying Wei ${ }^{1}$, Feng Zhang ${ }^{1}$, Shan Jiang ${ }^{3}$, Deliang Li ${ }^{4}$, \\ Guangzhao Peng ${ }^{3}$, Yilun $\mathrm{Yu}^{5,6}$ \& Xing $\mathrm{Xu}^{5,6 *}$
}

Tetanurae is a special group of theropod dinosaurs that originated by the late Early Jurassic. It includes several early-diverging groups of generally large-bodied predators (megalosauroids, allosauroids, tyrannosauroid coelurosaurs) as well as morphologically disparate small-bodied coelurosaurs, including birds. Aspects of the evolutionary history of tetanurans remain contested, including the topology of their deep phylogenetic divergences (among Megalosauroidea, Allosauroidea and Coelurosauria). We report a new theropod, Yunyangosaurus puanensis gen. et sp. nov., based on a fragmentary specimen recovered from the Middle Jurassic Xintiangou Formation of Chongqing, southwestern China. It shares several features uniquely with some megalosauroids (the clade of megalosaurids + spinosaurids + piatnitzkysaurids), such as prominent rims around the anterior articular surfaces of cervical centra and bifurcated anterior dorsal neural spines (present in piatnitzkysaurids). Nevertheless, it also shows several features that are rare or absent among megalosauroids and more crownward tetanurans, including prominent spinopostyzgopophyseal laminae (also present in non-tetanurans and metriacanthosaurid allosauroids), flat anterior articular surfaces of the cervical centra (also present in piatnitzkysaurids and some earlier-diverging tetanurans), and the presence of a posterior pneumatic foramen or fossa (absent in most tetanurans, but sporadically present in some cervical vertebrae of piatnitzkysaurids). Yunyangosaurus therefore presents a combination of derived and apparently primitive character states that are not seen in other theropods. This suggests that patterns of morphological evolution associated with deep tetanuran divergences were more complex than currently recognized, with implications for understanding the character evolution in theropods.

The Middle and Upper Jurassic Shaximiao Formation of southwestern China has produced spectacular fossil remains of dinosaurs and many other vertebrates ${ }^{1,2}$. Significant discoveries from this formation in the Chongqing area include the sauropods Mamenchisaurus hochuanensis, Omeisaurus changshouensis, and the theropod Yangchuanosaurus shangyouensis ${ }^{3}$ as well as the stegosaur Chungkingosaurus jiangbeiensis ${ }^{4}$. Compared to the

\footnotetext{
${ }^{1}$ Chongqing Laboratory of Geoheritage Protection and Research, No. 208 Hydrogeological and Engineering Geological Team, Chongqing Bureau of Geological and Mineral Resource Exploration and Development, Chongqing, 400700, China. ${ }^{2}$ Department of Earth Sciences, University of Oxford, Oxford, OX1 3AN, UK. ${ }^{3}$ Zigong Dinosaur Museum, Zigong, 643013, Sichuan, China. ${ }^{4}$ Chongqing Institute of Geological Survey, Chongqing, 401122, China. ${ }^{5}$ Key Laboratory of Vertebrate Evolution and Human Origins of Chinese Academy of Sciences, Institute of Vertebrate Paleontology and Paleoanthropology, Chinese Academy of Sciences, Beijing, 100044, China. ${ }^{6}$ CAS Center for Excellence in Life and Paleoenvironment, Beijing, China. *email: dhui6251@qq.com; xu.xing@ivpp.ac.cn
} 


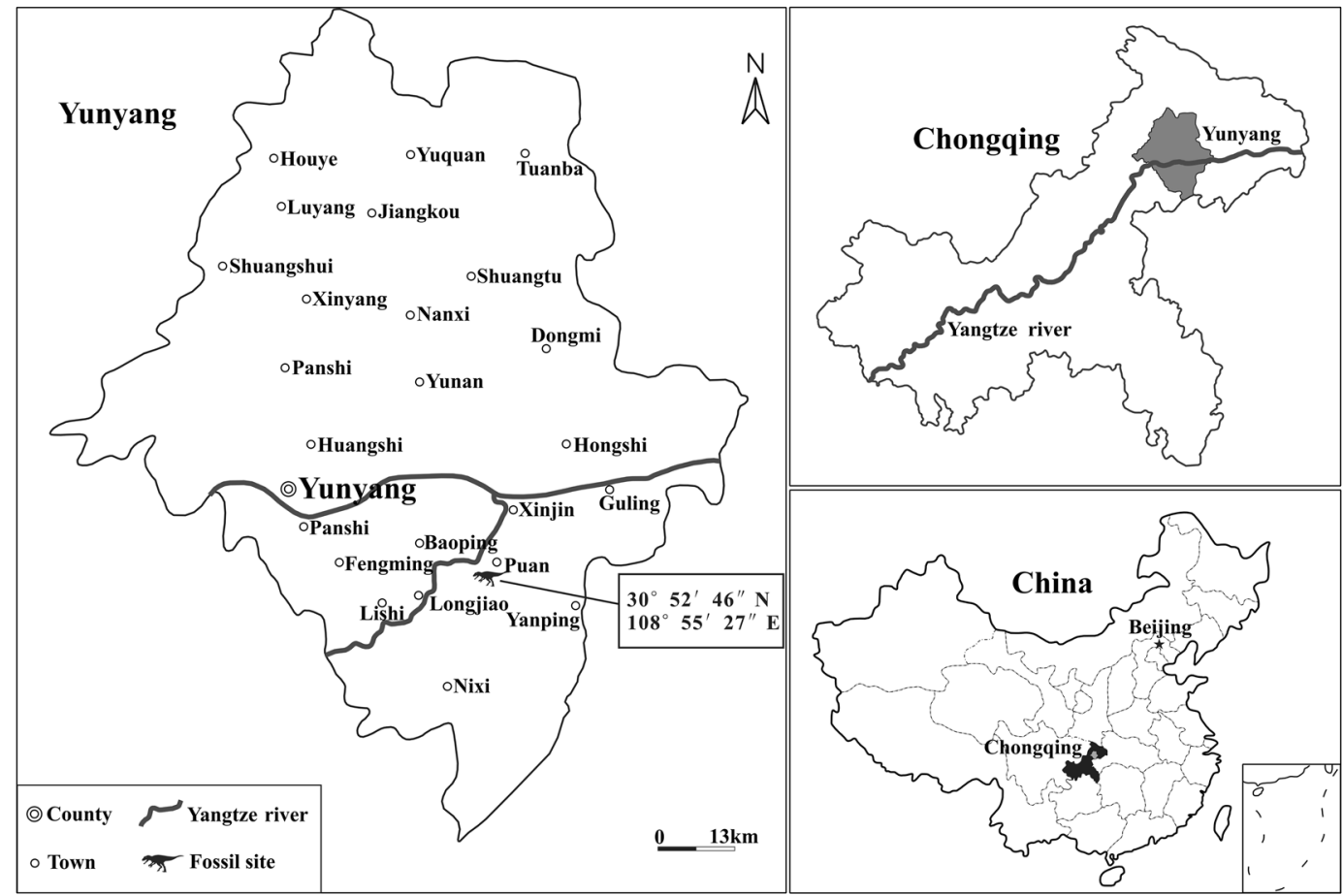

Figure 1. Geographical map indicating the location of the fossil site within the Yunyang County, Chongqing Municipality, China. Modified from Li.

fossiliferous Shaximiao Formation, the underlying lower Middle Jurassic Xintiangou Formation ${ }^{5,6}$ has produced few vertebrate fossils. In 2016, we organized a survey in the upper portion of the Xintiangou Formation of Laojun Village, Puan Township, Yunyang City, Chongqing (Fig. 1). This resulted in the discoveries of numerous vertebrate fossils, including a fragmentary theropod specimen recovered from a layer of gray lamellar shell siltstone intercalated with occasional silty mudstone (Fig. 2). The specimen comprises only some presacral vertebrae and several fragmentary bones, but it displays some informative features for its systematic position and provides new information on the early evolution of tetanuran dinosaurs. In the present paper, we establish a new tetanuran species based on this specimen, describe the specimen, and present a short discussion on its implications for the evolution of anatomical character states among early tetanurans.

\section{Results}

Systematic palaeontology

Theropoda Marsh 1881

Tetanurae Gauthier 1986

Yunyangosaurus puanensis gen. et sp. nov.

Etymology. Generic name is a combination of Yunyang (the county-level city in which the type locality is located) and sauros (Greek, reptile). The specific name is derived from Puan (the town name of the type locality).

Holotype. CLGPR v00002 (Chongqing Laboratory of Geoheritage Protection and Research), a partial skeleton comprising eleven presacral vertebrae, several cervical and dorsal ribs and chevrons. These bones are disarticulated, but were found associated in a small area about 5 square metres, with no other theropod skeletal elements preserved nearby.

Locality and horizon. Laojun Village, Puan Township, Yunyang City, Chongqing, China (Fig. 2). Middle Jurassic Xintiangou Formation ${ }^{5,6}$. It should be noted that a recent $\mathrm{U}-\mathrm{Pb}$ dating of the lowest beds of the overlying Shaximiao Formation suggested that the Shaximiao Formation started deposition in late Oxfordian ${ }^{7}$, but that study has not been widely accepted ${ }^{5}$. Furthermore, our newly collected unpublished $\mathrm{U}-\mathrm{Pb}$ dating data support the traditional view that lower beds of Shaximiao Formation is Middle Jurassic in age.

Diagnosis. An early-branching tetanuran distinguishable from other tetanurans by the following unique combination of features (*indicates autopomorphies): axial intercentrum sub-triangular in lateral view (sub-rectangular in Allosaurus and Sinraptor); mediolateral width of axial centrum tapers ventrally, resulting in a subtriangular outline in posterior view*; axis with an accessory medial spinopostzygapophyseal lamina* and a ball-like structure at the base of anterior margin of the axial neural spine*; axis bears very prominent spinopostzygopophyseal lamina similar to non-tetanuran theropods and metriacanthosaurids such as Sinraptor, but different from most tetanurans, including other Chinese Jurassic tetanurans and piatnitzkysaurids; cervical 


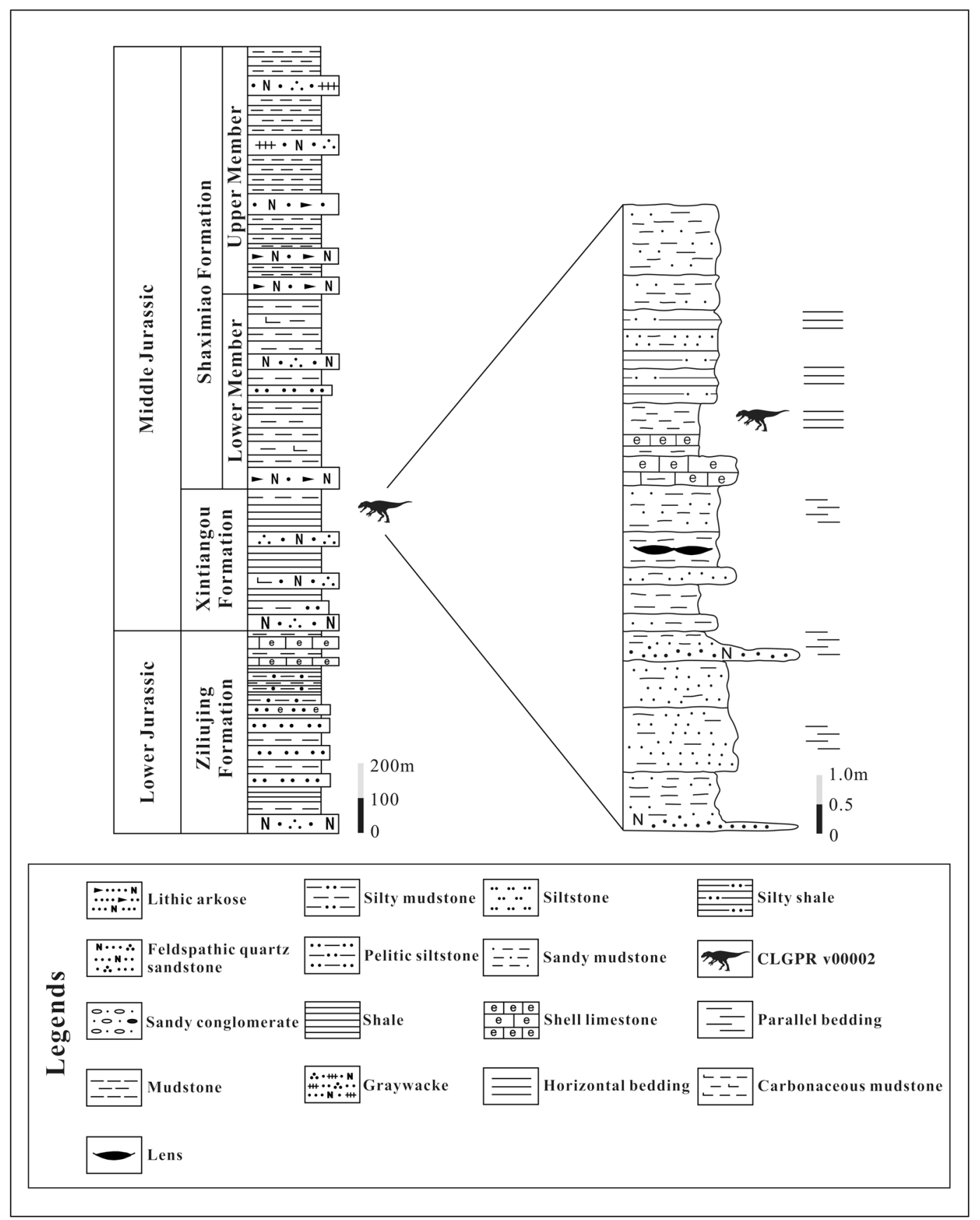

Figure 2. Stratigraphic section of the sedimentary sequence at the type locality. Modified from Li.

centra with flat anterior articular surfaces, similar to non-tetanurans, Condorraptor, Piatnitzkysaurus and some Jurassic Chinese tetanurans such as 'Szechuanosaurus' zigongensis and Xuanhanosaurus, but different from most other non-coelurosaurian tetanurans, which have convex anterior surfaces, including Leshansaurus, Marshosaurus Monolophosaurus and metriacanthosaurids such as Sinraptor; ventral ridge present in anterior cervicals (absent in most tetanurans, but present in some non-tetanurans and the piatnitzkysaurid Marshosaurus as a low, anterior eminence); posterior pneumatic foramen or fossa present in some cervical centra (also present in some of the pneumatic centra of Piatnitzkysaurus and Condorraptor and in all pneumatic centra of most non-tetanuran theropods; but absent in most tetanurans, including Chinese Jurassic tetanurans Gasosaurus, Leshansaurus, Sinraptor, 'Szechuanosaurus' zigongensis, Xuanhanosaurus and Yangchuanosaurus); prominent epipophyses present in posterior cervicals (absent or relatively low in other Chinese Jurassic tetanurans where known, such as Monolophosaurus, Sinraptor and 'Szechuanosaurus' zigongensis, as well as Carnotaurus, Torvosaurus, Condorraptor and Piatnitzkysaurus); cervical epipophyses prominent and posteriorly oriented* (posterolaterally oriented in most other theropods); posterior cervical and anterior dorsal vertebrae with transversely bifurcated neural spines*, especially prominent in anterior dorsals (less prominent bifurcated neural 


\begin{tabular}{|l|l|l|l|l|l|l|l|l|}
\hline Vert. No. & CL & PH & PW & MW & TH & NSH & NSL & NSW \\
\hline PV1 & 58 & 39 & 47 & 14 & 113 & 56 & 34 & 16 \\
\hline PV 2 & 69 & 48 & 50 & 15 & $102+$ & $42+$ & 32 & 8 \\
\hline PV 3 & 68 & 57 & 64 & 27 & - & - & - & - \\
\hline PV4 & 54 & 54 & $55+$ & 24 & - & - & - & - \\
\hline PV5 & 70 & 59 & 68 & 31 & 106 & 53 & 17 & 10 \\
\hline PV6 & 58 & 62 & 70 & 29 & 178 & 98 & 20 & 18 \\
\hline PV7 & 61 & 61 & 68 & 30 & 168 & 85 & 20 & 14 \\
\hline PV8 & 61 & 54 & $52+$ & 36 & - & - & - & - \\
\hline PV9 & 52 & 61 & $54+$ & 25 & 164 & 90 & 18 & 17 \\
\hline PV10 & 60 & 60 & 65 & 32 & - & $78+$ & 30 & 18 \\
\hline PV11 & 63 & 57 & 67 & 28 & $151+$ & $71+$ & 37 & 14 \\
\hline
\end{tabular}

Table 1. Vertebral measurements (in millimetres) of Yunyangosaurus puanensis holotype. The vertebrae are named as PV1 to PV11 for the convenience of the description; Abbreviations: CL, centrum length; PH, centrum posterior end height; $\mathrm{PW}$, centrum posterior end width; MW, centrum middle portion width; TH, vertebra total height (measured at posterior end); NSH, neural spine height; NSL, neural spine anteroposterior length; NSW, neural spine width; + , incomplete measurements.

spines are present in anterior dorsals only in Condoraptor, Marshosaurus and Piatnitzkysaurus; but absent in Chinese Jurassic theropods where preserved, such as Sinraptor, Monolophosaurus, 'Szechuanosaurus'zigongensis and Yangchuanosaurus); prominent hypapophyses in anterior dorsal vertebrae (also seen in metriacanthosaurids, but small in Monolophosaurus and most other early-branching tetanurans); distinctive fossae immediately ventral to dorsal parapophyses*.

Description and comparisons. The Yunyangosaurus puanensis holotype is inferred to be a sub-adult individual based on the closure of neurocentral sutures in most preserved vertebrae. It has an estimated total body length of 4.7 meters based on the similarity of the measurements of several vertebrae (Table 1) to those of Sinraptor dongi $i^{8}$. It is therefore similar to species such as Gasosaurus constructus ${ }^{4}$ and Piatnitzkysaurus floresi from the late Early Jurassic of Argentina ${ }^{9}$. However, it is smaller in body size than most other known early-branching tetanurans from the Jurassic of China ${ }^{1,8}$ with the exception of Chuandongocoelurus, the type specimen of which is considerably smaller ${ }^{10,11}$.

Throughout our description, we aim to make comparisons with Chinese Jurassic tetanurans where possible. Among these taxa, Sinraptor, Yangchuanosaurus and Shidaisaurus are metriacanthosaurids ${ }^{10}$ with well-known and relatively similar anatomy to each other ${ }^{3,12-15}$. In general, we have compared Yunyangosaurus to Sinraptor as an almost complete representative of this clade. Other Chinese Jurassic tetanurans potentially occupy a wide range of phylogenetic positions among early-diverging tetanurans. However, extensive comparisons with some of these are more difficult. The referred materials of some taxa, such as Chuandongocoelurus and Kaijiangosaurus, are likely represented by specimens from multiple species ${ }^{10}$, so the status of materials that overlap with the preserved material of Yunyangosaurus is not clear and requires revision. These taxa are not compared to Yunyangosaurus in our description. Nevertheless, they show clear differences: referred vertebral centra of Chuandongocoelurus are proportionally elongate, and referred cervical vertebrae of Kaijiangosaurus have one pleurocoel on each central side and anteroposteriorly broad and transversely non-bifurcated neural spines ${ }^{11}$. Other taxa such as Gasosaurus, Leshansaurus, 'Szechuanosaurus' zigongensis and Xuanhanosaurus include overlapping, definitely referable material ${ }^{16}$. Of these, vertebrate of Leshansaurus, 'Szechuanosaurus' zigongensis are relatively complete and well-preserved ${ }^{17}$ whereas Xuanhanosaurus includes relatively few, incomplete vertebrate ${ }^{18}$ and Gasosaurus includes most presacral vertebrae, but they are incomplete and highly reconstructed by plaster, making their original morphology difficult to observe (IVPP $)^{4}$. All four are apparently different from the new taxon, as indicated in our diagnosis and the description below.

Eleven presacral vertebrae of Yunyangosaurus are preserved, seven of them are identified as cervical vertebrae, and four as dorsal vertebrae, based on their anatomy (e.g., the position of parapophysis, the orientation of diapophysis, and the presence of a hypapophysis). The cervical series is represented by two anterior cervicals, three middle cervicals, and two posterior cervicals (probably the posteriormost two cervicals). The dorsal series is represented by three anterior dorsal vertebrae (probably the anteriormost ones) and an anterior middle dorsal vertebra.

The axis is mostly preserved, missing the odontoid and part of left spinopostzygapophyseal lamina. The axial intercentrum is attached to the axial centrum, but the line of fusion is obviously visible (Fig. 3A,B). The axial intercentrum is sub-triangular in outline in lateral view. This is similar to the condition in many theropods, including Leshansaurus ${ }^{16}$, Marshosaurus (CMNH 21704), Monolophosaurus ${ }^{19}$, Piatnitzkysaurus ${ }^{9}$, 'Szechuanosaurus' zigongensis ${ }^{17}$ and Neovenator (Brusatte et al., 2008), but is unlike the sub-rectangular axial intercentra of some allosauroids: Sinraptor ${ }^{13}$ and Allosaurus ${ }^{20}$. The ventral surface of the axial intercentrum is horizontal, as in some non-tetanuran theropods, Piatnitzkysaurus ${ }^{9}$ and the possible megalosaurid Leshansaurus ${ }^{16}$. In contrast, the ventral surface of the intercentrum is inclined anterodorsally relative to the ventral surface of the axis, such 

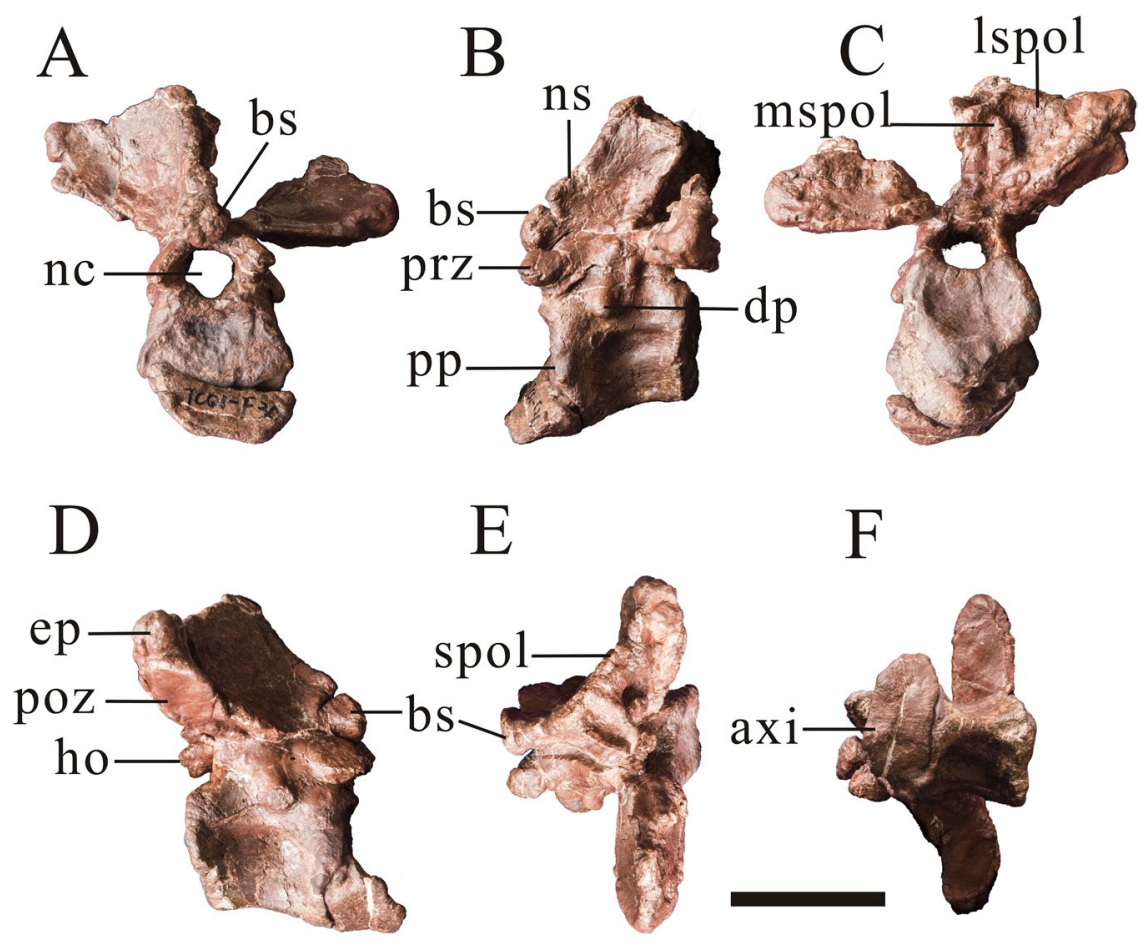

Figure 3. Axis (PV1, Table 1) of Yunyangosaurus puanensis holotype in anterior (A), left lateral (B), posterior (C), right lateral (D), dorsal (E) and ventral. (F) Axi, axial intercentrum; bs, ball-like structure; dp, diapophysis; ep, epipophysis; ho, hyposphene; nc, neural canal; ns, neural spine; poz, postzygapophysis; pp, parapophysis; prz, prezygapophysis; lspol, lateral spinopostzygapophyseal lamina; mspol, medial spinopostzygapophyseal lamina. Scale bar $=5 \mathrm{~cm}$.

that the two form an oblique angle as in Monolophosaurus ${ }^{19}$ and some allosauroids such as Acrocanthosaurus ${ }^{21}$, Giganotosaurus (IVPP V 7265) and Sinraptor ${ }^{13}$.

The axial centrum is platycoelous, with a flat anterior surface. The anterior articular surface of the axial centrum faces anterodorsally, as does the articular surface of the axial intercentrum for the atlantal intercentrum. The axial centrum bears a shallow fossa on its lateral surface on each side. These fossae are asymmetrically developed: the right one is large and shallow, but the left one is small and deep (Fig. 3B,D). This fossa, on the left side, is proportionally larger than those of many other tetanurans, including Allosaurus ${ }^{20}$, Sinraptor ${ }^{13}$, 'Szechuanosaurus' zigongensis ${ }^{17}$, Eustreptospondylus ${ }^{22}$ and Piatnitzkysaurus (PVL 4073). The ventral surface of the centrum is transversely narrow with a mediolateral width that tapers ventrally, but nevertheless it is transversely rounded and lacks a distinct ventral keel. This morphology may be an autapomorphy of Yunyangosaurus and is unlike the transversely broad ventral surface of the axial centrum in 'Szechuanosaurus' zigongensis (ZDM 9011), Yangchuanosaurus hepingensis (ZDM 0024), Allosaurus ${ }^{20}$, Sinraptor ${ }^{13}$ and Eustreptospondylus ${ }^{22}$. Piatnitzkysaurus (PVL 4073) and Marshosaurus (CMNH 21704) have transversely narrow axial centra and are therefore somewhat similar to Yunyangosaurus. However, the width of the axial centrum does not taper ventrally in these taxa, unlike in Yunyangosaurus. The posterior articular surface of the axial centrum of Yunyangosaurus has a sub-triangular outline when seeing in posterior view, and in lateral view it forms an acute angle with the ventral margin (Fig. 3C) to a greater degree than in Yangchuanosaurus ${ }^{18}$, Carnotaurus $^{23}$, Ceratosaurus ${ }^{24}$, or Sinraptor ${ }^{13}$. The neural canal of the axis is $17 \mathrm{~mm}$ high and $18 \mathrm{~mm}$ wide while the posterior articular surface is $39 \mathrm{~mm}$ high and $47 \mathrm{~mm}$ wide, indicating the presence of a relatively large neural canal.

The ventrolaterally oriented axial diapophysis is small and is situated at the fusion line of the centrum and neural arch. The axial prezygapophysis is relatively small and its articular surface faces anterodorsolaterally. The axial postzygapophyses are large with well-developed quadrangular articular surfaces, similar to those of more posterior presacral vertebrae. The articular surfaces face posteroventrally with a lateral inclination of about $20^{\circ}$ from horizontal (Fig. 3C). Prominent, broad epipophyses overhang the postzygapophyseal articular surfaces and their long axes are oriented slightly more medially than those of the postzygapophyses. Axial epipophyses are prominent in many non-tetanuran theropods, including Dilophosaurus ${ }^{25}$ and Carnotaurus ${ }^{23}$, as well as in piatnitzkysaurids (Piatnitzkysaurus ${ }^{9}$; Marshosaurus, CMNH 21704) and many allosauroids, including metriacanthosaurids such as Sinraptor ${ }^{13}$ and Shidaisaurus ${ }^{15}$, but are somewhat reduced in megalosaurids (Eustreptospondylus) $)^{10,22}$ and spinosaurids (Baryonyx) ${ }^{26}$.

There are two pairs of spinopostzygapophyseal laminae: a lateral one and a medial one. The prominent lateral one is the major one, and it is comparable to the spinopostzygapophyseal lamina reported in metriacanthosaurids such as Sinraptor ${ }^{13}$ and Shidaisaurus ${ }^{15}$, and in non-tetanuran theropods such as Ceratosaurus ${ }^{24}$ and Dilophosaurus ${ }^{25}$. In contrast, it is either small or absent in most early-branching tetanurans (e.g. Allosaurus ${ }^{20}$;

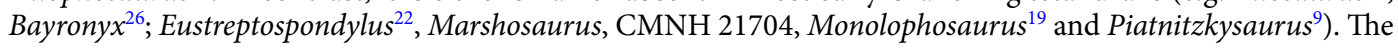


A

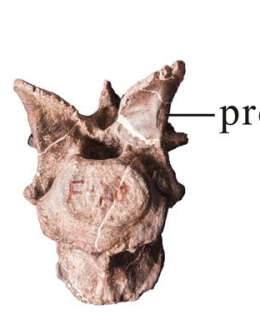

$\mathrm{B}$

$\mathrm{C}$
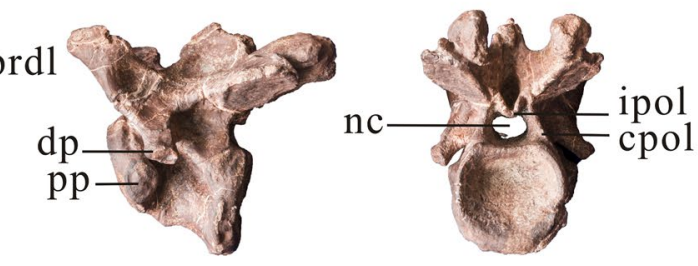

$\mathrm{D}$
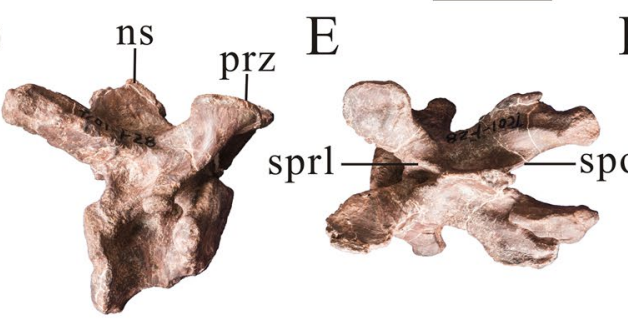

$\mathrm{F}$
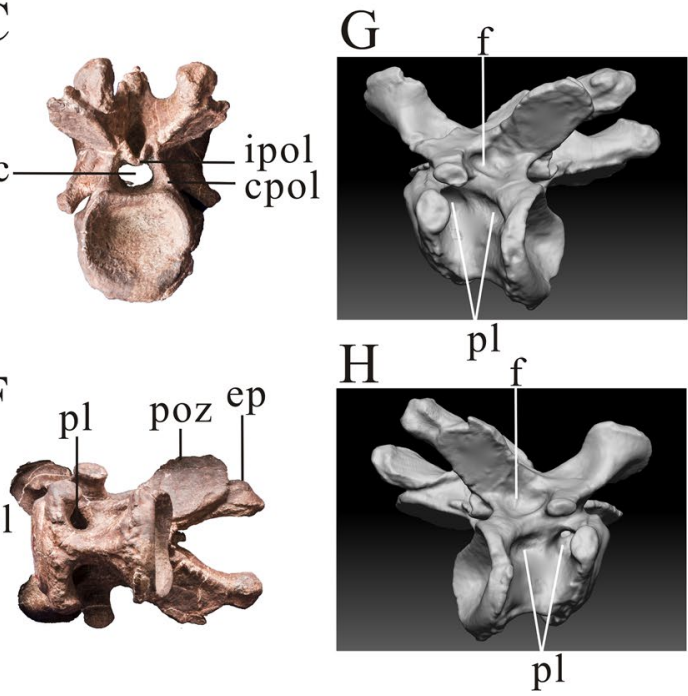

Figure 4. An anterior cervical vertebra (PV2, Table 1) of Yunyangosaurus puanensis holotype in anterior (A), left lateral (B), posterior (C), right lateral (D), dorsal (E), ventral (F) and 3D images $(\mathbf{G}, \mathbf{H})$. cpol centropostzygapophyseal lamina; dp, diapophysis; ep, epipophysis; f, fossa; ipol, intrapostzygapophyseal lamina; nc, neural canal; ns, neural spine; pl, pneumatic foramen (pleurocoel); poz, postzygapophysis; pp, parapophysis; prdl, prezygodipophyseal lamina; prz, prezygapophysis; spol, spinopostzygapophyseal lamina; sprl, spinoprezygapophyseal lamina. Scale bar $=5 \mathrm{~cm}$.

second, more medially located spinopostzygapophyseal lamina, is oriented vertically and is located within the fossa on the posterior surface of the axial neural spine, between the more lateral spinopostzygapophyseal lamina and the central portion of the neural spine. This medial spinopostzygapophyseal lamina has not been reported in other theropods and may be an autapomorphy of Yunyangosaurus.

The neural spine of the axis is posterodorsally oriented (Fig. 3F) as in many other theropods, including Yangchuanosaurus hepingensis (ZDM 0024), Allosaurus ${ }^{20}$, and Sinraptor ${ }^{13}$. The anterior margin of the neural spine does not extend anteriorly beyond the prezygapophysis, unlike in other non-tetanuran theropods such as Coelophysis ${ }^{27}$, Dilophosaurus ${ }^{25}$, Carnotaurus ${ }^{23}$, and Ceratosaurus ${ }^{24}$. The anterior margin of the neural spine is thickened toward its anteroventral end, and develops into a ball-like structure. This feature has not been reported in other theropods and may be an autapomorphy of Yunyangosaurus.

The preserved anterior postaxial cervical vertebra is playtcoelous, with an essentially a flat or weakly convex anterior surface. This also occurs in most non-tetanuran theropods ${ }^{28}$, the piatnitzkysaurids Condorraptor and Piatnitzkysaurus ${ }^{9,29}$ and the Chinese Jurassic tetanurans 'Szechuanosaurus' zigongensis $^{17}$, Xuanhanosaurus ${ }^{18}$ and figured cervical vertebra of Chuandongocoelurus and Kaijiangosaurus ${ }^{11}$. In contrast, most other tetanurans have convex anterior surfaces of their cervical centra ${ }^{28}$, including Monolophosaurus ${ }^{19}$, megalosaurids such as Leshansaurus ${ }^{16}$ and metriacanthosaurids such as Sinraptor ${ }^{13}$. The posterior articular surface is concave. The perimeter of the anterior articular surface of the centrum forms a distinct flattened rim (Fig. 4). This condition is widespread among megalosauroids and is a proposed synapomorphy of the group megalosaurids, piatnitzkysaurids and spinosaurids ${ }^{10,22,26,30}$. The centrum is considerably longer anteroposteriorly than dorsoventrally in lateral view, with a length:height ratio of 1.44. It is slightly wider transversely than dorsoventrally in posterior view (Table 1). The centrum is invaded by two pneumatic foramina on each lateral side, an anterior and a posterior foramen. The anterior foramen is deep, penetrating into the body of the centrum. However, the posterior one is shallow in the anterior cervical vertebra, taking the form of a fossa that does not penetrate the centrum. Nevertheless, a deep, penetrating posterior pneumatic foramen is present in some of the other cervical centra (described below). The posterior pneumatic foramen is widely-distributed among non-tetanuran theropods, but is absent in most tetanurans ${ }^{28,31}$. The posterior pneumatic foramen is variably present in some individual cervical and pectoral vertebrae of Piatnitzkysaurus (PVL 4073). A well-defined sharp-edged fossa of corresponding size and position to the posterior pneumatic foramen in present in a middle cervical vertebrae of Condorraptor ${ }^{29}$. The pneumatic foramina of the anterior cervical centrum of Yunyangosaurus are situated at the upper part of the centrum in lateral view, while that are situated at the middle part of the subsequent centra. The ventral surface of the centrum is mediolaterally thin in ventral view and concave in side view, and bear a low, anteroposteriorly oriented ridge.

The neural arch is invaded ventrolaterally by pneumatic fossae as in many theropods, including Ceratosaurus $^{24}$, Torvosaurus ${ }^{30,32}$, Piatnitzkysaurus ${ }^{9}$, Allosaurus $^{24}$, Carnotaurus $^{23}$, and Sinraptor ${ }^{13}$. In Allosaurus ${ }^{20}$ and Monolophosaurus ${ }^{19}$, the lateral fossae of anterior cervical neural arches are shallow compared to those of Sinraptor ${ }^{13}$ and Yunyangosaurus puanensis. A horizontal interprezygapophyseal lamina connects the prezygapophyses on the anterior surface of the neural arch. This lamina forms the dorsal roof of the neural canal anteriorly, and the ventral floor of a triangular fossa on the anteroventral surface of the neural arch, together with the 
A

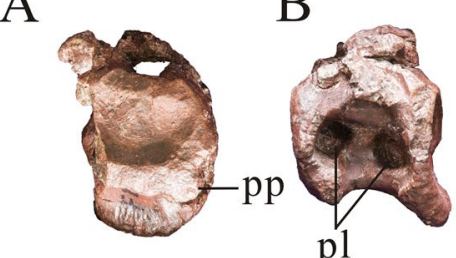

$\mathrm{C}$

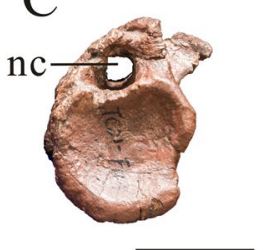

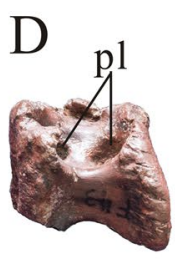

$\mathrm{H}$

I
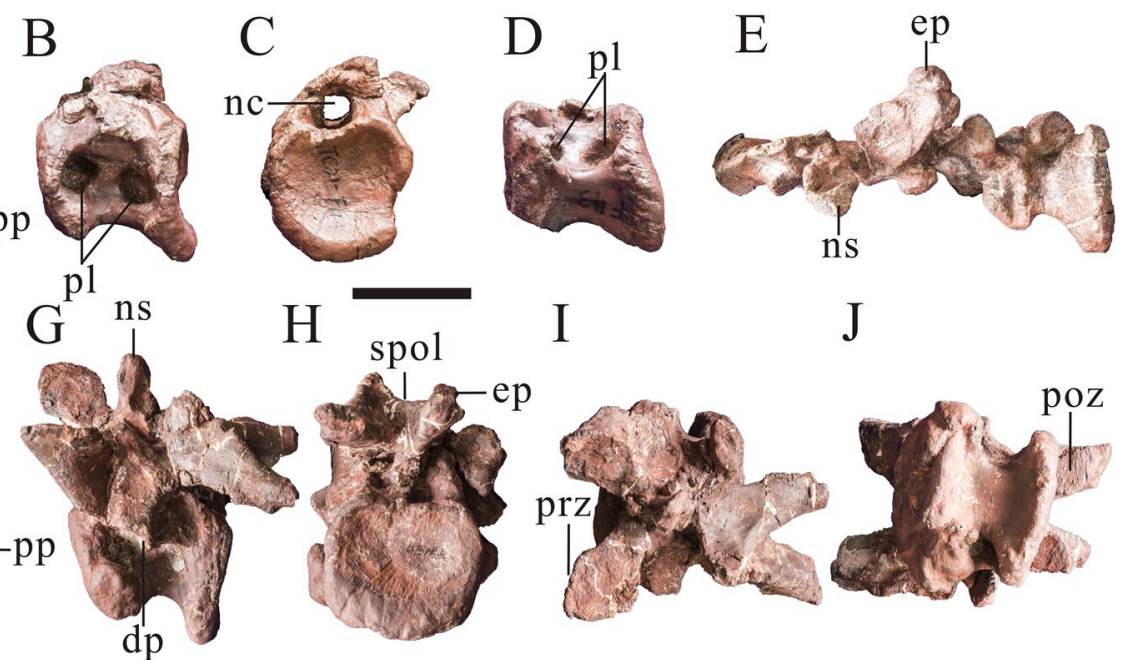

$\mathrm{J}$

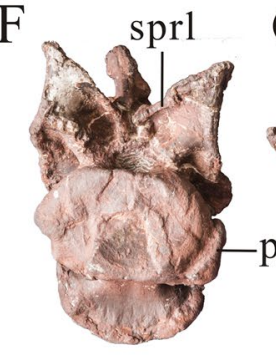

$\mathrm{dp}$
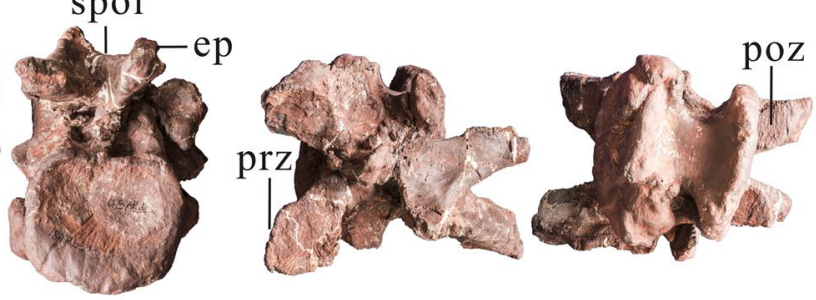

Figure 5. Three middle cervical vertebrae of Yunyangosaurus puanensis holotype. The anterior one (PV3, Table 1) in anterior (A), left lateral (B), in posterior $(\mathbf{C})$ and right lateral (D) views; the middle one (PV4, Table 1) in dorsal view (E); the posterior one (PV5, Table 1) in anterior (F), left lateral (G), posterior (H), right lateral (I) and dorsal (J) views. cpol centropostzygapophyseal lamina; dp, diapophysis; ep, epipophysis; ipol, intrapostzygapophyseal lamina; nc, neural canal; ns, neural spine; pl, pneumatic foramen (pleurocoel); poz, postzygapophysis; pp, parapophysis; prdl, prezygodipophyseal lamina; prz, prezygapophysis; spol, spinopostzygapophyseal lamina; sprl, spinoprezygapophyseal lamina. Scale bar $=5 \mathrm{~cm}$.

spinoprezygapophyseal laminae. The spinopostzygapophyseal laminae and the interpostzygapophyseal laminae bound a much broader, rhomb-shaped fossa on the posterior surface of the neural spine.

The diapophyses are located at the fusion line of the centrum and neural arch. They are inclined ventrolaterally as in other theropods such as Sinraptor and; Piatnitzkysaurus ${ }^{9,13}$. The articular surface of prezygapophysis is approximately circular, while the articular surface of postzygapophysis is a long oval shape. The epipophyses are prominent, extending well beyond the posterior margins of the postzygapophyses, and they are oriented posteriorly rather than posterolaterally as in most other theropods $s^{9,19,20,30,33}$. The presence of prominent and strongly posteriorly-directed epipophyses of the anterior cervical vertebrae may therefore be an autapomorphy of Yunyangosaurus. The neural spine is plate-like and posterodorsally oriented, proportionally shorter than in Ceratosaurus $^{24}$ and Allosaurus ${ }^{20}$. The prespinal and postspinal ridges are prominent.

The middle cervical vertebrae are platycoelous (Fig. 5). The centra are slightly longer anteroposteriorly than dorsoventrally in lateral view (Table 1). The posterior articular surfaces are wider transversely than high dorsoventrally, whereas the anterior articular surfaces are smaller, and are higher dorsoventrally than the posterior articular surfaces (Fig. 5B,F) (Table 1). As with the anterior cervicals, the centra are invaded by two pneumatic foramina on each side. But unlike the anterior cervicals, the ventral surfaces of middle cervical vertebrae are broad and flat. The neural arch of the third cervical vertebra is fairly complete, and the upper margin of the neural canal connects the prezygapophyses forming an elongated fossa with the spinoprezygapophyseal laminae in anterior view. The prezygapophysis of the cervical $\mathrm{cm} 3$ are large and its articular surfaces face anterodorsolaterally. The postzygapophyses of the cervical $\mathrm{cm} 3$ are large with well-developed quadrangular articular surfaces, and prominent epipophyses overhang the postzygapophyses. The neural spines are club-shaped and vertical. They are relatively slender mediolaterally and anteroposteriorly, resulting in a finger-like appearance.

The posterior cervicals are also platycoelous (Figs. 6 and 7). Paired fossae are located ventrally on the anterior surface of the neural spine. These fossae are bounded by the spinoprezygapophyseal laminae laterally and the prezygapophyses ventrally, and are separated on the midline by the prespinal ridge of the neural spine (Fig. 7A). Paired fossae are also present on the posterior surface of the neural arch, bounded ventrally by the dorsal margin of the neural canal, the centropostzygapophyseal laminae and the intrapostzygapophyseal laminae. These fossae are deeper in the penultimate cervical than in the posteriormost one (Figs. 6C and 7C). The centra of the posterior cervicals are invaded by only one pneumatic foramen (the anterior pneumatic foramen) on each lateral side. The posterior pneumatic foramen is absent, unlike in more anterior cervicals. The pneumatic foramina are entirely circular and are deep, penetrating well into the body of the centrum and invading the posterior surfaces of the parapophyses. The articular surfaces of prezygapophyses are approximately circular and dorsolateral, while the articular surfaces of postzygapophyses are long oval and ventrolateral. The epipophyses are extend posteriorly to a level that is slightly posterior to the postzygapophyses. The prespinal and postspinal ridge are more prominent in the posteriormost cervical. The diapophysis originates just dorsal to the level of the neural canal and curves ventrolaterally along its length (Fig. 7F). Three large fossae are located on the lateral surface of the neural arch, ventral to the base of the diapophysis: the infraprezygapophyseal fossa, infradiapophyseal fossa and infrapostzygapophyseal fossa. These fossae are bounded by the prezygodipophyseal lamina, the paraprezygapophyseal lamina, the paradiapophyseal lamina, the posterior centrodiapophyseal lamina, the intrapostzygapophyseal lamina and the postzygadiapophyseal lamina. The infraprezygapophyseal fossa and infrapostzygapophyseal fossa are 


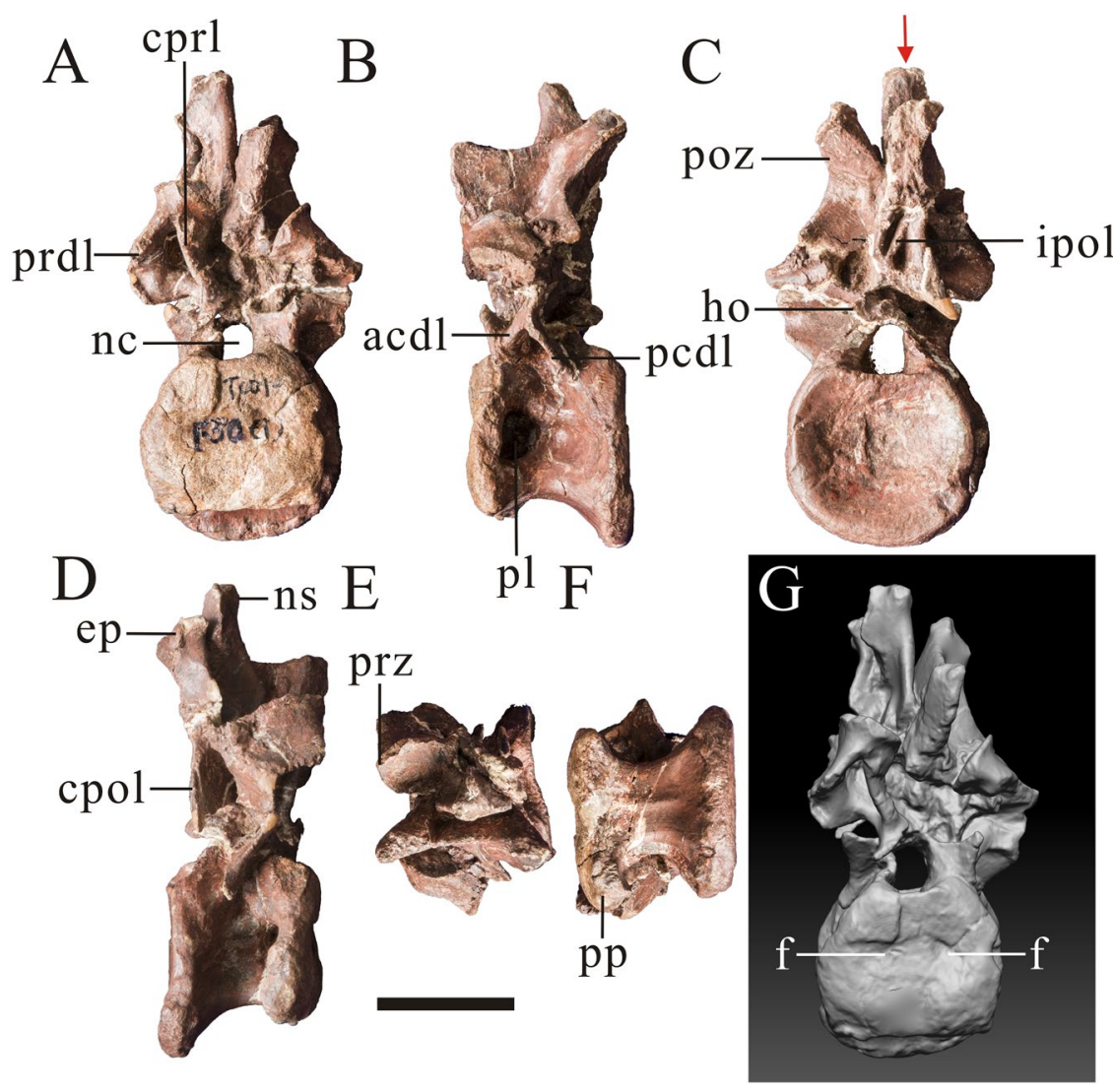

Figure 6. Penultimate cervical vertebra (PV6, Table 1) of Yunyangosaurus puanensis holotype in anterior (A), left lateral (B), posterior (C), right lateral (D), dorsal (E), ventral (F) and 3D image (G) views. acdl, anterior centrodiapophseal lamina; cpol centropostzygapophyseal lamina; cprl, centroprezygapophyseal lamina; ep, epipophysis; f, fossa; ho, hyposphene; ipol, intrapostzygapophyseal lamina; nc, neural canal; ns, neural spine; pcdl, posterior centrodiapophyseal lamina; pl, pneumatic foramen (pleurocoel); poz, postzygapophysis; pp, parapophysis; prdl, prezygodipophyseal lamina; prz, prezygapophysis. The red arrow directs bifurcation of the neural spine. The red arrow directs bifurcation of the neural spine. Scale bar $=5 \mathrm{~cm}$.

irregularly quadrilateral, but the infradiapophyseal fossa is triangular (Fig. 7D). In anterior view, the bottom of the right postzygapophyses lamina develop two large and deep fossae divided by a prominent rige, while only one small and deep fossa developed beneath the bottom of the left postzygapophyses lamina. In the posterior view, the bottom of each postzygadiapophyseal lamina develop a deep fossa, and an obvious ridge can be seen beneath the bottom of the right postzygadiapophyseal lamina (Fig. 7A,C). The neural spines of the posterior cervicals are slender in lateral view and their apices are slightly bifurcate (Figs. 6C, 7A,C).

The three anteriormost dorsal vertebrae of Yunyangosaurus have platycoelous centra. This is similar to the condition in most theropods, although the first four or five dorsals of Acrocanthosaurus may be opisthocoelous ${ }^{34}$. The ratio of the anteroposterior length of centrum to the height of the posterior articular surface of centrum is 0.85 to 1.13 among anterior dorsal vertebrae of Yunyangosaurus, and the ratio of height to width of the posterior articular surface of centrum is 0.85 to 0.92 . The anterior articular surfaces of the centra are marked by a well-developed circumferential groove, and two shallow fossae are also present on the anterior articular surfaces of all dorsals, located just dorsal to mid-height (Figs. 8D,J and 9A). The anterior articular surfaces of the dorsals are roughly circular and posterior articular surfaces are nearly square.

The central portion of each dorsal centrum is transversely constricted relative to the articular surfaces. Distinct, single pneumatic foramina invade the lateral surfaces of the centra posterior to the parapophyses in anterior dorsals. Pneumatic foramina are present only in the cervical and anterior dorsal centra of Yunyangosaurus, and are absent from more posterior dorsals. This is similar to the condition in many Jurassic theropods ${ }^{35}$, for example, the posteriormost centrum to bear a pneumatic foramen is the $14^{\text {th }}$ presacral of Sinraptor ${ }^{13}$ and the $13^{\text {th }}$ presacral of Allosaurus ${ }^{20}$. Nevertheless, pneumatic foramina in more posterior dorsal centra are present in geologically younger members of many groups of theropods and take various morphologies ${ }^{35}$. For example, large pneumatic openings are found in all dorsal centra of Torvosaurus ${ }^{30}$. There is one conspicuous fossa beneath each parapophysis in all of the preserved dorsals of Yunyangosaurus. Radial grooves are present on the posteroventral surface of the centrum in anterior dorsals (Fig. 8H,I). The hypapophyses are also prominent in the anterior dorsals. Prominent hypoapophyses are widely-distributed among adult tetanurans, including Allosaurus ${ }^{20}$, Condoraptor ${ }^{29}$, Marshosaurus (CMNH 21704), Sinraptor ${ }^{13}$, Piatnitzkysaurus ${ }^{9}$ and Streptospondylus ${ }^{36}$. The most prominent hypapophysis of Allosaurus is in the second dorsal (Madsen, 1976), which is the $11^{\text {th }}$ presacral vertebra, as in Sinraptor ${ }^{13}$. 


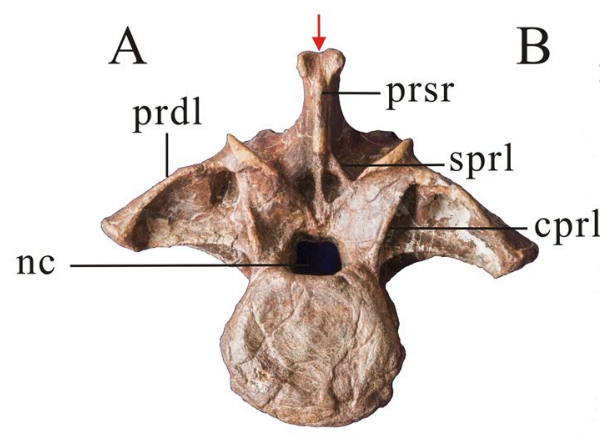

$\mathrm{D}$

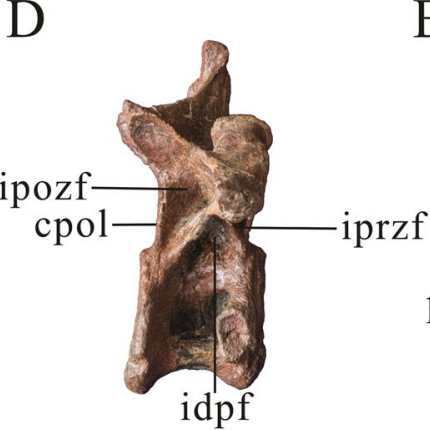

B

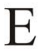

$\mathrm{E}$

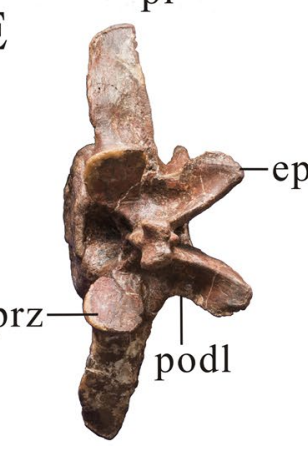

$\mathrm{C}$

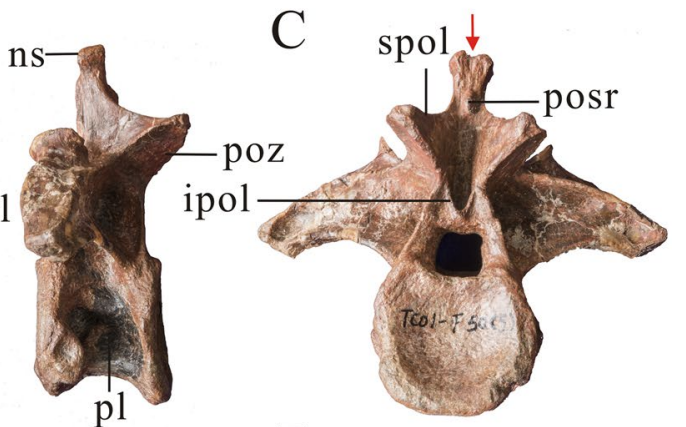

$\mathrm{F}$

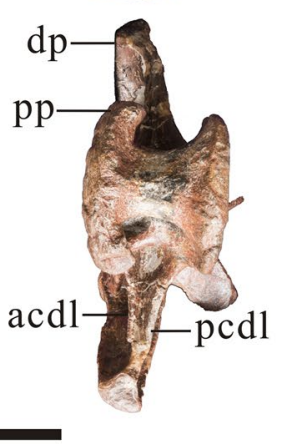

Figure 7. Last cervical vertebra (PV7, Table 1) of Yunyangosaurus puanensis holotype in anterior (A), left lateral (B), posterior (C), right lateral (D), dorsal (E) and ventral (F). acdl, anterior centrodiapophseal lamina; cpol centropostzygapophyseal lamina; cprl, centroprezygapophyseal lamina; dp, diapophysis; ep, epipophysis; idpf, infradiapophyseal fossa; ipol, intrapostzygapophyseal lamina; ipozf, infrapostzygapophyseal fossa; iprzf, infraprezygapophyseal fossa; nc, neural canal; ns, neural spine; pcdl, posterior centrodiapophyseal lamina; pl, pneumatic foramen (pleurocoel); podl, postzygadiapophyseal lamina; posr, postspinal ridge; poz, postzygapophysis; pp, parapophysis; prdl, prezygodipophyseal lamina; prsr, prespinal lamina; prz, prezygapophysis; spol, spinopostzygapophyseal lamina; sprl, spinoprezygapophyseal lamina. The red arrows direct bifurcation of the neural spine. Scale bar $=5 \mathrm{~cm}$.

The hyposphenes are large in the anterior dorsals and have a roughly constant transverse width dorsoventrally. This differs from the ventrally-wide, triangular hyposphene morphology that is found among many early-diverging tetanurans ${ }^{37}$. Step-like ridges are present lateral to the hyposphenes, running posterodorsally from the dorsal border of neural canal to the posterior edge of postzygapophyses (Figs. 6C and 8C). These ridges have a homoplastic distribution among early-diverging tetanurans being present both among meaglosauroids and in metriacanthosaurids ${ }^{37}$. The spinopostzygapophyseal lamina extends posterodorsally to the posterolateral margin of the neural spine from the posterior corner of the postzygapophysis. The prespinal and postspinal ridges are developed in the anterior dorsals (Fig. 8A,C). The spinopostzygapophyseal laminae are developed in the anterior dorsals. The articular surface of the diapophysis is trapeziform and slightly concave (Fig. 8B). Below the base of the diapophysis, there are three large fossae called infraprezygapophyseal fossa, infradiapophyseal fossa and infrapostzygapophyseal fossa, which on the lateral surface of the base of the neual arch. These fossae are formed by the prezygodipophyseal lamina, the paraprezygapophyseal lamina, the paradiapophyseal lamina, the posterior centrodiapophyseal lamina, the intrapostzygapophyseal lamina and the postzygadiapophyseal lamina. The infraprezygapophyseal fossa and infrapostzygapophyseal fossa are irregularly quadrilateral, but the infradiapophyseal fossa is triangular (Fig. 8B). The bottom of the prezygodipophyseal laminae develop two small ridges (one is the prezygodiapophyseal ridge) and some small shallow fossae in the anterior dorsal. The neural spine is claviform in the anterior dorsals and the tops of the anterior dorsals are transversely bifurcated as in the posterior cervicals, but the bifurcation is deeper than in the latter. The articular surface of prezygapophyses are approximately circular, while the articular surface of postzygapophyses are oval.

The centrum of the preserved anterior middle dorsal is amphiplatyan. The amphiplatyan condition is present in all dorsals of Carnotaurus ${ }^{23}$, whereas it is only present from the fifth dorsal ( $14^{\text {th }}$ presacral) and more posteriorly in Allosaurus ${ }^{20}$ and from the sixth ( $15^{\text {th }}$ presacral) of Monolophosauurus ${ }^{19}$. Clear, radial grooves can be found in the anteroventral and posteroventral portions of the centrum (Fig. 9F). A shallow depression is present on the lateral surface of this centrum in Yunyangosaurus. This may be homologous to the large, extensive, fossa-like pneumatic foramina that are present in the anterior dorsal centra of some megalosaurids such as Torvosaurus and Eustreptospondylus s $^{10,22,30}$, though it is relatively shallow, and not pronounced as in those taxa.

The neural canal of the anterior middle dorsal is $11 \mathrm{~mm}$ high and $8 \mathrm{~mm}$ wide while the anterior articular surface is $23 \mathrm{~mm}$ high and $25 \mathrm{~mm}$ wide, so the neural canal is about $1 / 3$ to $1 / 2$ as big as the centrum (Fig. 9A). The hypantrum is highly developed and the ridges of the middle portion between the dorsal margin of the neural canal and the junction of the prezygapophyses are developed. These ridges are called intraprezygapophyseal laminae. They contact the articular surfaces of the prezygapophyses, forming two triangular fossae with the margin 


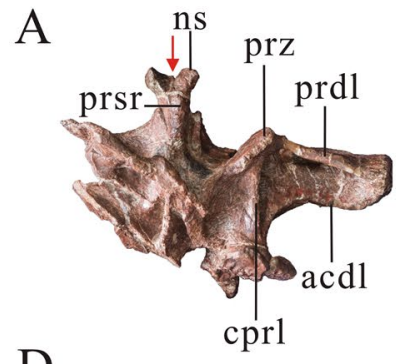

D

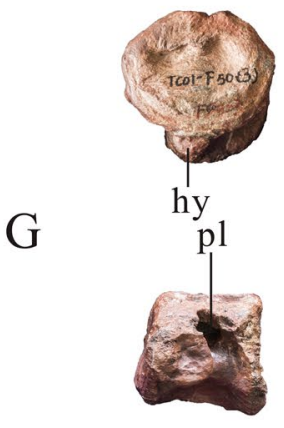

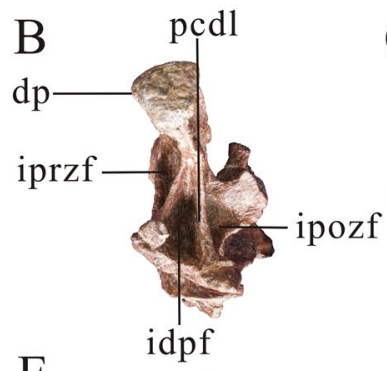

E

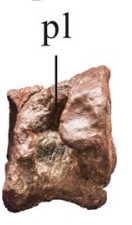

$\mathrm{H}$

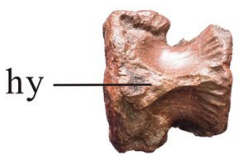

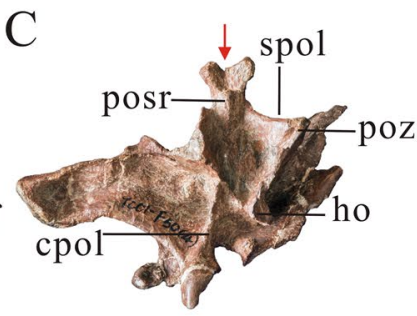

F

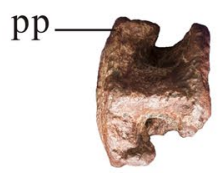

I

L

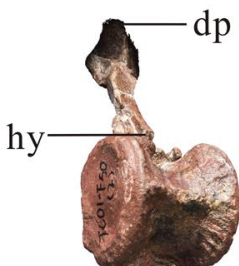

$\mathrm{J}$

K
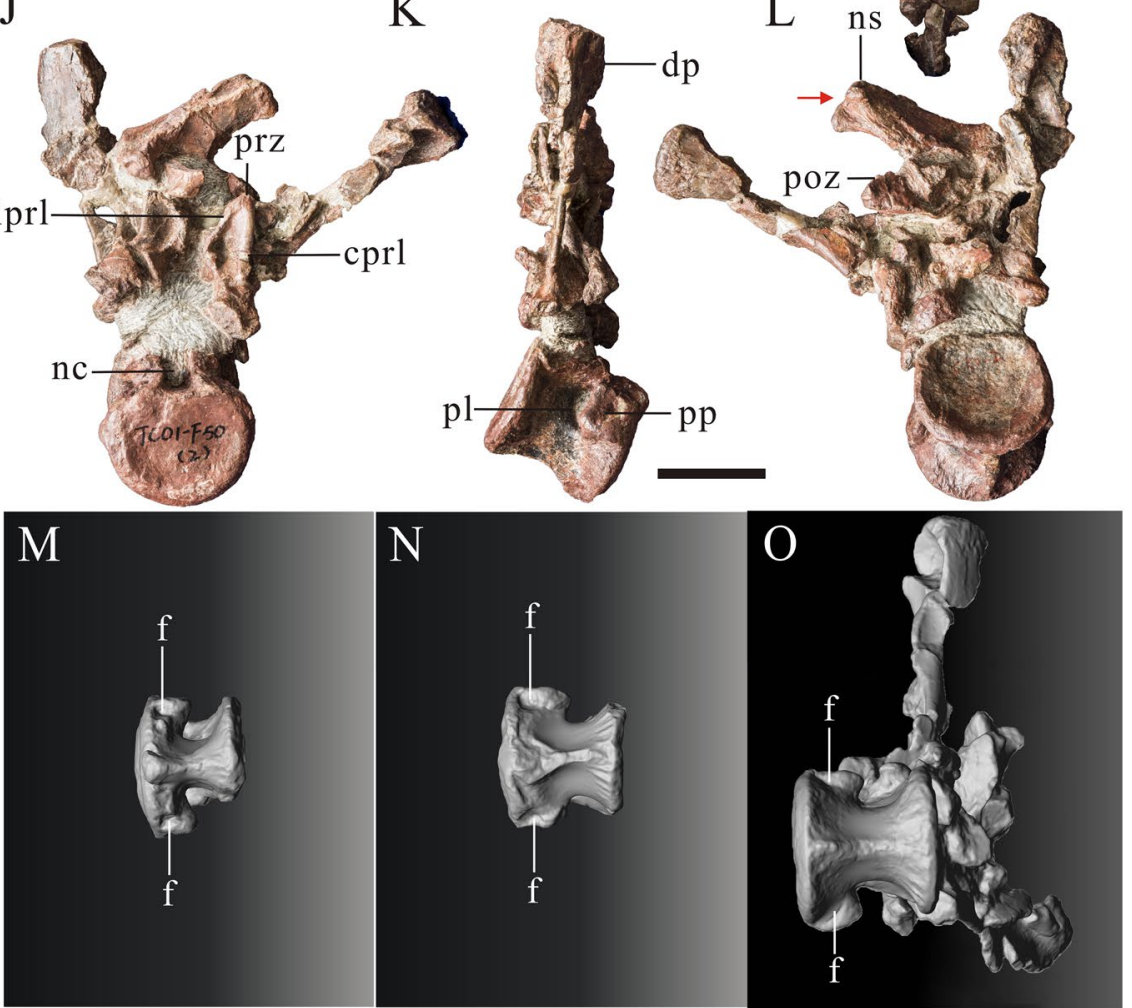

Figure 8. Three anteriormost dorsal vertebrae of Yunyangosaurus puanensis holotype. Dorsal 1 (PV9, Table 1) in anterior (A), left lateral (B), in posterior (C); Dorsal 2 (PV8, Table 1) in anterior (D), right lateral (E), ventral (F); Dorsal 3 in left lateral (G), ventral (H); Dorsal 3 (PV10, Table 1) in ventral (I), anterior (J), right lateral (K), posterior (L) and 3D images (M-O). acdl, anterior centrodiapophseal lamina; cpol centropostzygapophyseal lamina; cprl, centroprezygapophyseal lamina; dp, diapophysis; f, fossa; hy, hypapophysis; ho, hyposphene; idpf, infradiapophyseal fossa; ipozf, infrapostzygapophyseal fossa; iprzf, infraprezygapophyseal fossa; iprl, intraprezygapophyseal lamina; nc, neural canal; ns, neural spine; pcdl, posterior centrodiapophyseal lamina; pl, pneumatic foramen (pleurocoel); posr, postspinal ridge; poz, postzygapophysis; pp, parapophysis; prdl, prezygodipophyseal lamina; prsr, prespinal rige; prz, prezygapophysis; spol, spinopostzygapophyseal lamina. The red arrows direct bifurcation of the neural spine. Scale bar $=5 \mathrm{~cm}$. 


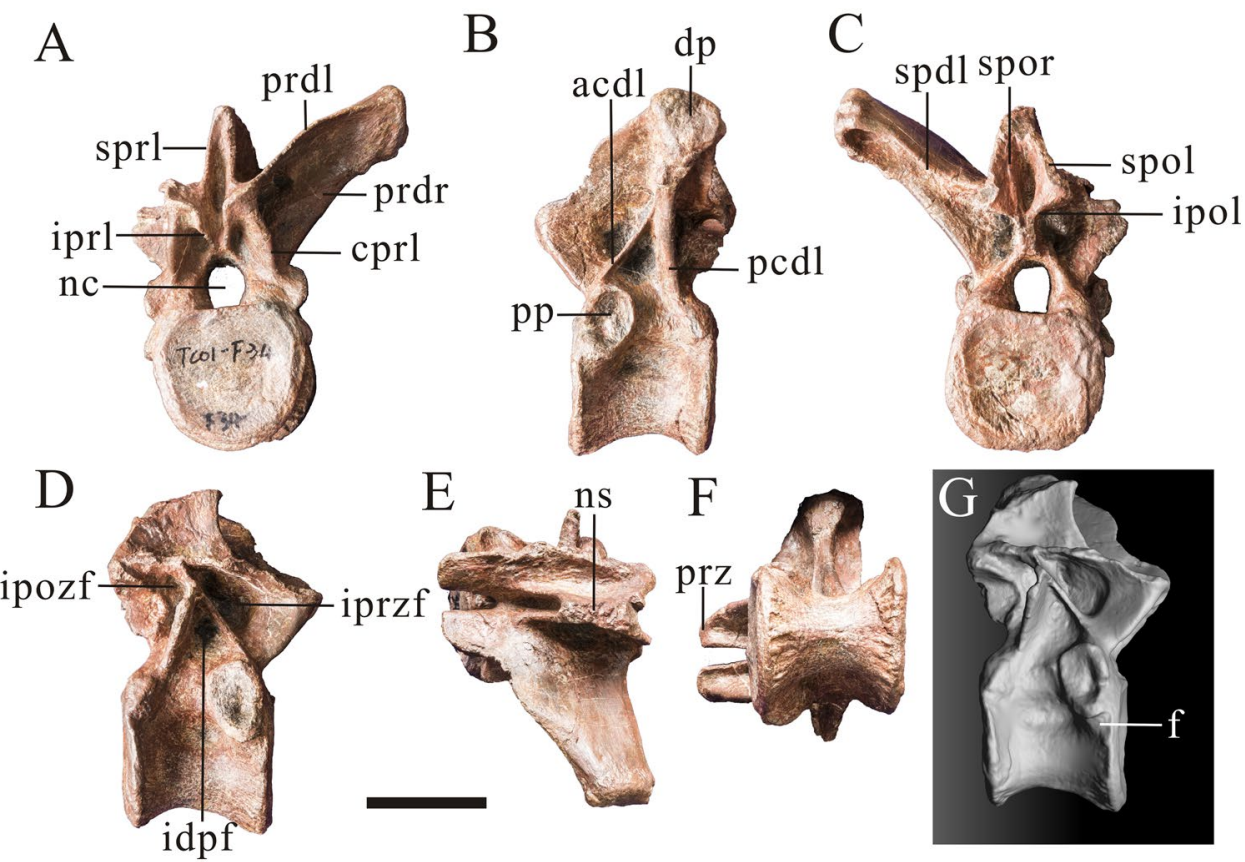

Figure 9. An anterior middle dorsal vertebra (PV11, Table 1) of Yunyangosaurus puanensis holotype in anterior (A), left lateral (B), posterior (C), right lateral (D), dorsal (E), ventral (F) and 3D image (G). acdl, anterior centrodiapophseal lamina; cprl, centroprezygapophyseal lamina; dp, diapophysis; f, fossa; idpf, infradiapophyseal fossa; ipol, intrapostzygapophyseal lamina; ipozf, infrapostzygapophyseal fossa; iprl, intraprezygapophyseal lamina; iprzf, infraprezygapophyseal fossa; nc, neural canal; ns, neural spine; pcdl, posterior centrodiapophyseal lamina; pl, lateral depression (pleurocoel); pp, parapophysis; prdl, prezygodipophyseal lamina; prdr, prezygodiapophyseal ridge; prz, prezygapophysis; spdl, spinodiapophyseal lamina; spol, spinopostzygapophyseal lamina; spor, spinspinopostzygapophyseal ridge; sprl, spinoprezygapophyseal lamina. Scale bar $=5 \mathrm{~cm}$.

of the neural canal and anterior centroprezygapophyseal laminae (Fig. 9A). The hyposphene is smaller in the anterior middle dorsal than in the anterior dorsals. A ridge is visible on the spinopostzygapophyseal lamina of the anterior/middle dorsal, while it is missing in the anterior dorsal (Fig. 9C). The spinoprezygapophyseal and spinopostzygapophyseal laminae are developed in the anterior middle dorsal. The spinoprezygapophyseal lamina is obvious in the anterior middle dorsal but only a gentle ridge in the anterior dorsals (Fig. 9A). The diapophyses are upswept and below the base of which are three large fossae called infraprezygapophyseal fossa, infradiapophyseal fossa and infrapostzygapophyseal fossa, on the lateral surface of the base of the neual arch. These fossae are formed by the prezygodipophyseal lamina, the paraprezygapophyseal lamina, the paradiapophyseal lamina, the posterior centrodiapophyseal lamina, the intrapostzygapophyseal lamina and the postzygadiapophyseal lamina. The infraprezygapophyseal fossa and infrapostzygapophyseal fossa are irregularly quadrilateral, but the infradiapophyseal fossa is triangular (Fig. 9D). In the infrapostzygapophyseal fossa, the centropostzygapophyseal ridge is visible in the anterior middle dorsal but illegible in the anterior dorsals (Fig. 9B). The neural spine is incompletely preserved, but it is inferred to be plate-like (Fig. 9A).

Two proximal portions of the cervical ribs are preserved. The capitulum and tuberculum are widely separated, and the articular facets lie in the same plane, so presumably they belong to posterior cervicals. Deep fossae are found between the base of the capitulum, tuberculum, and prominent anterolateral process. The angle between the capitulum and tuberculum is about $70^{\circ}$. Some partial dorsal ribs are preserved. The capitulum and tuberculum are more widely separated, and the proximal pneumatopore is absent. The cross-sectional shapes of the ribs are subcircular.

Three unforked chevrons with bridged haemal canal are preserved, and the haemal cannal is short approximately $20 \%$ chevron length (Fig. 10).

\section{Discussion}

Yunyangosaurus puanensis is represented by limited material, but it displays numerous informative features for its systematic position and taxonomy. It is highly likely a tetanuran dinosaur based on the general morphology of the presacral vertebrae, and in particular several tetanuran or orinoidan synapomorphies are present ${ }^{10,38}$ : the axial neural spine is narrow anteroposteriorly and somewhat rod-like; the prezygapophyses of anterior cervical vertebrae are enlarged and situated entirely lateral to the neural canal; and there is a pronounced ventral keel in the anterior dorsal vertebrae.

However, Yunyangosaurus puanensis also lacks several derived features seen in most other early-branching tetanurans $s^{10,38}$. These features include strongly opisthocoelous cervical centra, cervical vertebrae with only one pair of pneumatic foramina (rather than two, including both the anterior and posterior pneumatic foramen, as in 


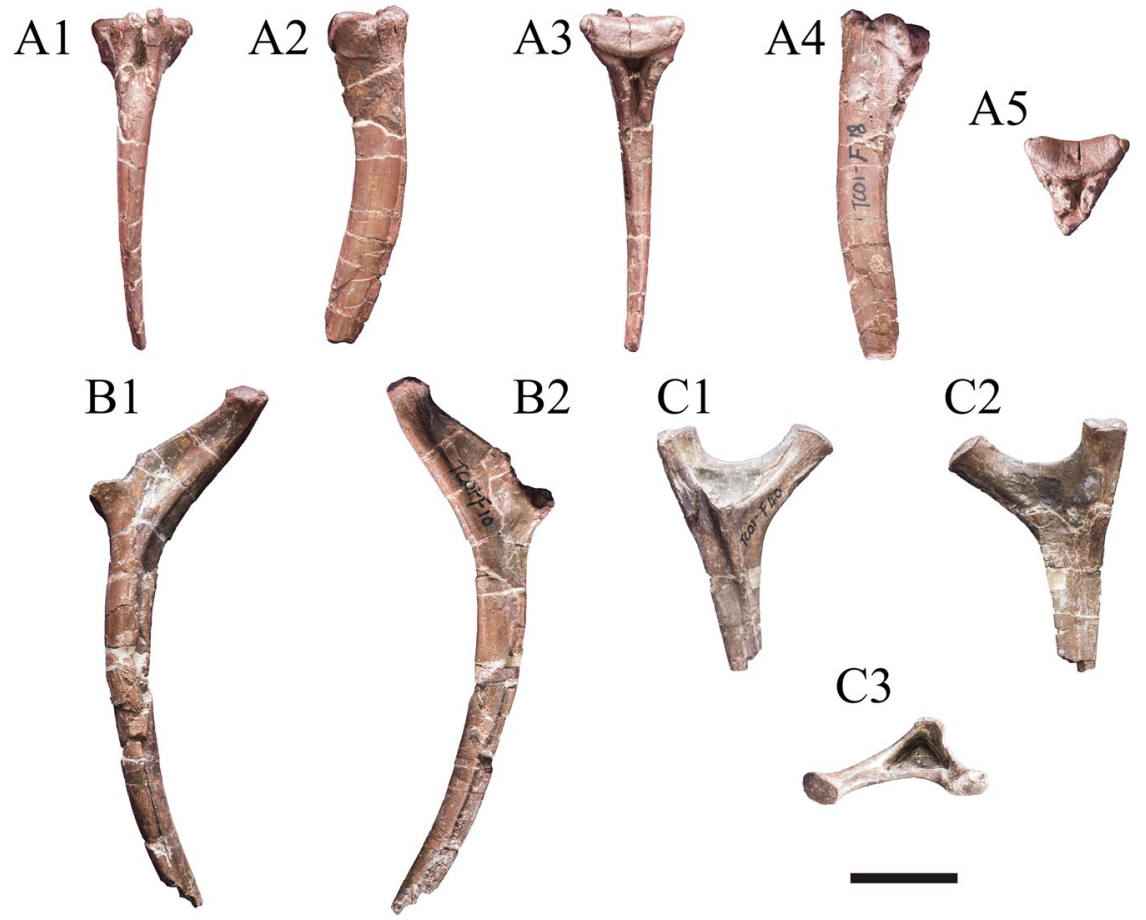

Figure 10. A partial chevron (A1-A5) and two ribs (B1-B2 are dorsal ribs, $\mathrm{C} 1-\mathrm{C} 3$ are cervical ribs) of Yunyangosaurus puanensis holotype.

most non-tetanuran theropods), and the presence of prominent axial spinopostzygapophyseal laminae. Although the anterior surfaces of the anterior cervical centra of Yunyangosaurus puanensis are weakly convex, this is unlike the prominent, convexity seen in the opisthocoelous condition that is widespread among early-diverging tetanurans. Furthermore, the middle and posterior cervical vertebrae of Yunyangosaurus are strictly platycoelous with flat anterior surfaces. Among tetanurans, this morphology, with flat to weakly convex anterior surfaces of the cervical centra, is also present in 'Szechuanosaurus' zigongensis (ZDM 9011), the piatnitzkysaurid Piatnitzkysaurus ${ }^{9}$, Xuanhanosaurus ${ }^{18}$ and Condorraptor ${ }^{39}$. Furthermore, the presence of a second, posterior, pneumatic formamen is variably present in some cervical centra of Piatnitzkysaurus ${ }^{35}$, although it is much more prominently and consistently developed in Yunyangosaurus, similar to the condition in most non-tetanuran theropods ${ }^{28}$. The axial spinopostzygapophyseal lamina is reduced in most tetanurans, unlike in Yunyangosaurus. Among tetanurans, a prominent axial spinopostzygapophyseal lamina is also present in metriacanthosaurids such as Sinraptor ${ }^{13}$.

Yunyangosaurus puanensis also lacks an axial intercentrum with an anterodorsally inclined ventral surface. This feature is present in many early-branching tetanurans including Monolophosaurus ${ }^{19}$ and Sinraptor ${ }^{13}$. However, the ventral surface of the axial intercentrum of Yunyangosaurus is horizontal similar to the condition in some megalosauroids, such as Leshansaurus and Piatnitzkysaurus ${ }^{9,16}$.

Yunyangosaurus possesses several features that are only known in some megalosauroids, especially piatnitzkysaurids (described above). These also include the presence of a prominent rim round articular surface of cervicals ${ }^{10}$ and bifurcated anterior dorsal neural spines (present in piatnitzkysaurids) ${ }^{7}$. A numerical cladistic analysis was then ran to assess this phylogenetic hypothesis (see Methods), but which fails to place Yunyangosaurus within the Megalosauroidea and instead posits it in an unresolved position with many other tetanurans (Fig. 11). Noteworthy is also that the inclusion of Yunyangosaurus in the dataset led to collapsing of the Megalosauroidea and the Coelurosauria. This suggests the complex combination of character states in Yunyangosaurus has an impact on the tetanuran phylogeny, which is still far from robust for understanding the evolution of the group. However, we reran the analysis using implied weighting (see Methods), and this analysis places Yunyangosaurus within the Megalosauroidea in an unresolved position with many other megalosauroids (Fig. 12).

The discovery of Yunyangosaurus has implication for our understanding of character evolution of tetanuran theropods. For example, Yunyangosaurus displays several features that are generally absent in most other tetanurans, and these features include the presence of posterior pneumatic foramina throughout the cervical series and in particular pneumatic foramen in middle cervical centra (also present occasionally in some cervical centra of piatnitzkysaurids), prominent spinopostyzgopophyseal laminae (also present in metriacanthosaurids), and flat anterior articular surfaces of the cervical centra (also present in piatnitzkysaurids).

However, currently our knowledge of Yunyangosaurus is relatively incomplete, preventing us from attaining a more complete understanding of its affinities among early tetanurans. For now, Yunyangosaurus serves to highlight the potentially complex character distribution of character states of the axial column among early-branching tetanurans, and especially among Chinese Jurassic tetanurans. 


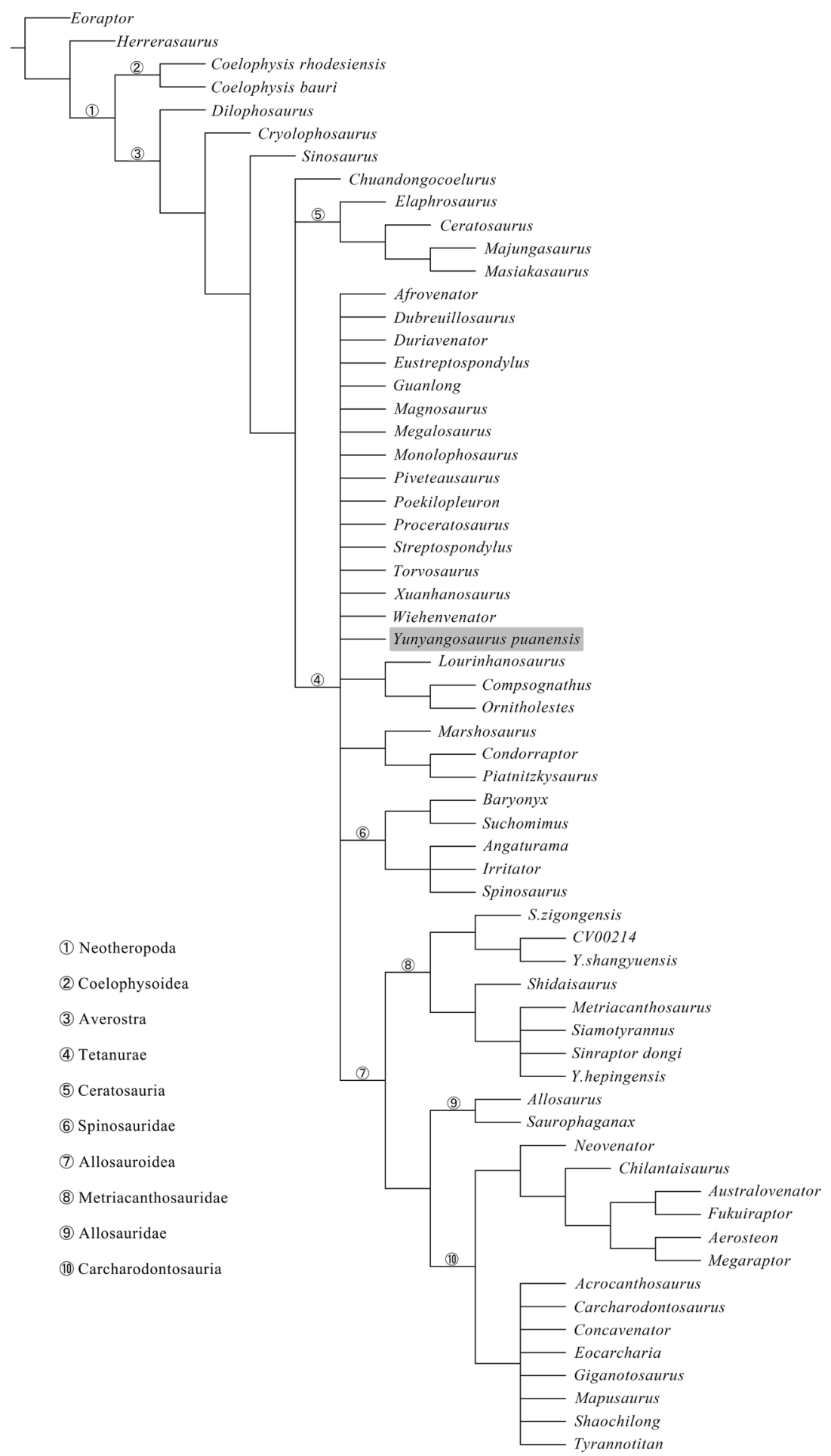

Figure 11. Strict consensus of 4860 most parsimonious trees produced by our analysis showing the systematic position of Yunyangosaurus puanensis.

\section{Methods}

Phylogenetic analysis. We added Yunyangosaurus into a comprehensive dataset for tetanuran phylogeny ${ }^{40}$, and the final matrix includes 351 characters and 63 operational taxonomical units (OTUs). The matrix was analyzed using TNT $1.5^{41}$, with the 'New Technology' search option, using a driven search that stabilized consensus twice with a factor of 25 , and default settings for sectorial, ratchet, tree drift and tree fusion. The resulting 142 most parsimonious trees (MPTs) with a tree length $=1103$ step, a CI $=0.39$, and a $\mathrm{RI}=0.67$ were then subjected to tree bisection and reconnection (TBR) branch swapping, and finally 4860 MPTs were found. The strict 


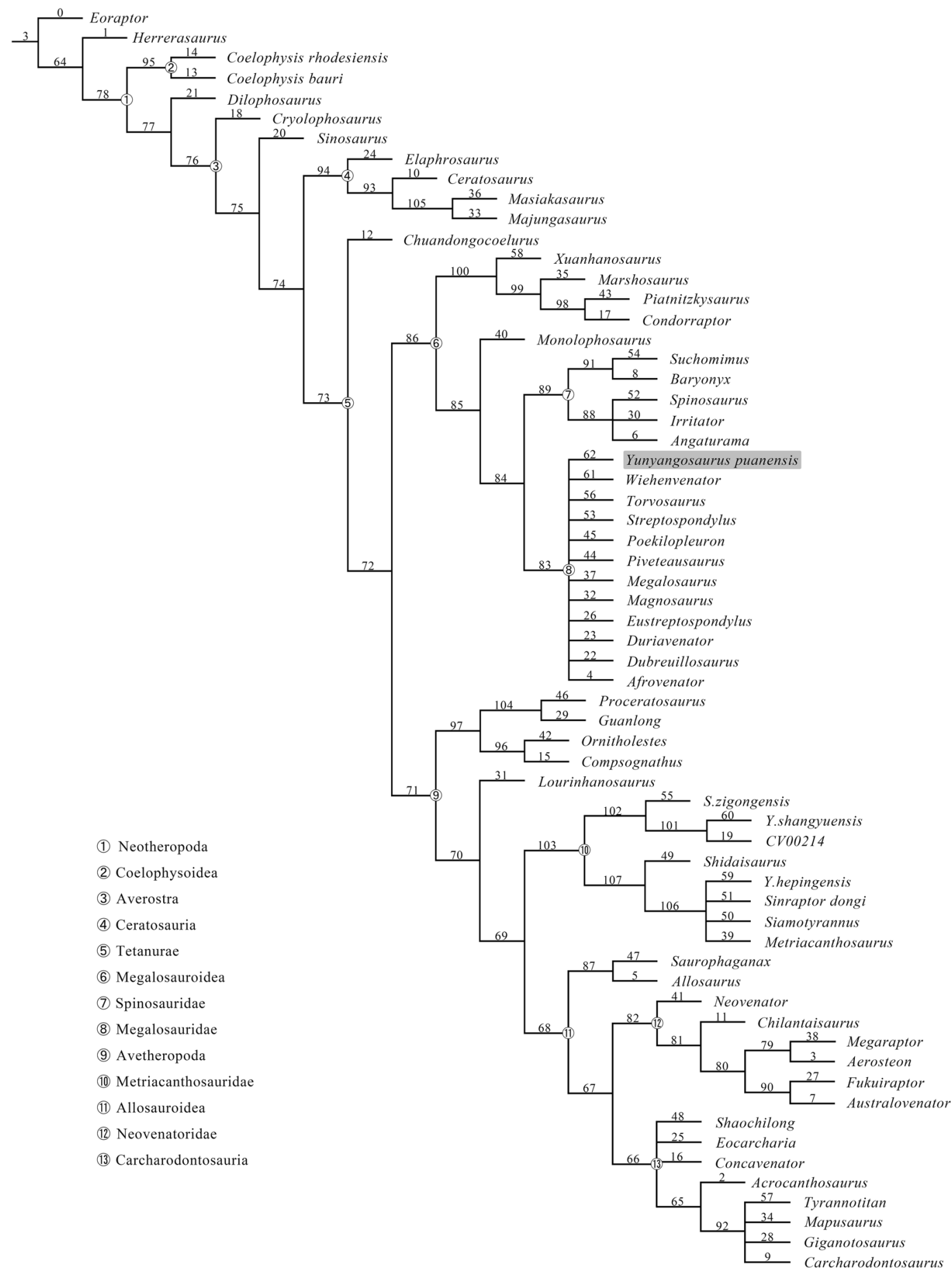

Figure 12. Strict consensus of 1107 most parsimonious trees produced by our parsimonious analysis with implied weighting showing the systematic position of Yunyangosaurus puanensis.

consensus of these 4860 MPTs places Yunyangosaurus at the base of the Tetanurae in an unsolved position with several other early-branching tetanuran theropods. However, we reran the analysis using implied weighting parsimony with a k value of 8.0, and this analysis places Yunyangosaurus within the Megalosauroidea in an unresolved position with many other megalosauroids (Fig. 12).

Received: 24 June 2019; Accepted: 25 November 2019;

Published online: 10 January 2020 


\section{References}

1. Dong, Z. M., Zhou, S. \& Zhang, Y. The dinosaurian ramians from Sichuan Basin. China. Paleontol Sinica, n.s. C 23, 1-145 (1983).

2. Peng, G., Ye, Y., Gao, Y., Shu, C. \& Jiang, S. Jurassic dinosaur faunas in Zigong. (Sichuan Renmin Press, Chengdu, 2005).

3. Gao, Y. Yangchuanosaurus hepingensis - a new species of carnosaur from Zigong, Sichuan. Vertebrata PalAsiatica 30, 313-324 (1992).

4. Dong, Z. \& Tang, Z. A new Mid-Jurassic theropod (Gasosaurus constructus gen. et sp. nov.) from Dashanpu, Zigong, Sichuan Province, China. Vertebrata Palasiatica 23, 77-83 (1985).

5. Huang, D. Jurassic integrative stratigraphy and timescale of China. Science China Earth Sciences 62, 223-255 (2019).

6. Fang, Y., Liu, Y., Zhang, Y. \& Wang, B. Elemental analysis and calcification characteristics of ostracods from the Middle Jurassic Xintiangou Formation in eastern Sichuan provience, China (in Chinese). Acta Palacontologica Sinica 51, 96-101 (2012).

7. Wang, S. et al. Extreme ontogenetic changes in a ceratosaurian theropod. Current Biology 27, 144-148 (2017).

8. Currie, P. \& Xijin, Z. A new carnosaur from the Jurassic of Xinjiang, People’s Republic of China. Canadian Journal of Earth Sciences (1993).

9. Bonaparte, J. F. Les dinosaures (carnosaures, allosauridés, sauropodes, cétiosauridés) du Jurassique Moyen de Cerro Cóndor (Chubut, Argentine). Annales de Paléontologie 72, 247-289 (1986).

10. Carrano, M. T., Benson, R. B. \& Sampson, S. D. The phylogeny of Tetanurae (Dinosauria: Theropoda). Journal of Systematic Palaeontology 10, 211-300 (2012).

11. He, X. The Vertebrate Fossils of Sichuan (in Chinese). (Sichuan Science and Technology Press, 1984).

12. Gao, Y. A complete carnosaur skeleton from Zigong, Sichuan: Yangchuanosaurus hepingensis. Sichuan Science and Technology Press, Chengdu, 1-100 (1999).

13. Currie, P. J. \& Zhao, X. A new carnosaur (Dinosauria, Theropoda) from the Jurassic of Xinjiang, People's Republic of China. Canadian Journal of Earth Sciences 30, 2037-2081 (1993).

14. Dong, Z., Zhang, Y., Li, X. \& Zhou, S. A new carnivorous dinosaur of Yongchuan, Sichuan. Chinese Science Bulletin 23, 302-304 (1978).

15. Wu, X., Currie, P. J., Dong, Z., Pan, S. \& Wang, T. A new theropod dinosaur from the Middle Jurassic of Lufeng, Yunnan, China. Acta Geologica Sinica-English Edition 83, 9-24 (2009).

16. Li, F., Peng, G., Ye, Y., Jiang, S. \& Huang, D. A new carnosaur from the Late Jurassic of Qianwei, Sichuan, China. Acta Geologica Sinica 83, 1203-1213 (2009).

17. Gao, Y. A new species of Szechuanosaurus from the Middle Jurassic of Dashanpu, Zigong, Sichuan. Certebrata Palasiatica, 6 (1993).

18. Dong, Z., Zhou, S. \& Zhang, Y. Dinosaurs from the Jurassic of Sichuan basin, China. Palaeontologia Sinica (new series C) 162, 1-145 (1983).

19. Zhao, X., Benson, R. B., Brusatte, S. L. \& Currie, P. J. The postcranial skeleton of Monolophosaurus jiangi (Dinosauria: Theropoda) from the Middle Jurassic of Xinjiang, China, and a review of Middle Jurassic Chinese theropods. Geological Magazine 147, 13-27 (2009).

20. Madsen, J. H. Jr. Allosaurus fragilis: a revised osteology. Utah Geological and Mining Survey Bulletin 109, 1-163 (1976).

21. Harris, J. D. A Reanalysis of Acrocanthosaurus atokensis, its Phylogenetic Status, and Paleobiogeographic Implications, Based on a New Specimen from Texas: Bulletin 13. Vol. 13 (New Mexico Museum of Natural History and Science, 1998).

22. Sadleir, R., Barrett, P. M. \& P, P. H. The anatomy and systematics of Eustreptospondylus oxoniensis, a theropod dinosaur from the Middle Jurassic of Oxfordshire, England. Monograph of the Palaeontographical Society, London 162, 1-82 (2008).

23. Bonaparte, J. F., Novas, F. E. \& Coria, R. A. Carnotaurus sastrei Bonaparte, the horned, lightly built carnosaur from the Middle Cretaceous of Patagonia. Contrib. in sci./Natural history nuseum of Los Angeles county 419, 1-41 (1990).

24. Gilmore, C. W. Osteology of the carnivorous Dinosauria in the United States National museum: with special reference to the genera Antrodemus (Allosaurus) and Ceratosaurus. (US Government printing office, 1920).

25. Welles, S. P. Dilophosaurus wetherilli (Dinosauria, Theropoda). Osteology and comparisons. Palaeontographica Abteilung A, 85-180 (1984).

26. Charig, A. J. \& Milner, A. C. Baryonyx walkeri, a fish-eating dinosaur from the Wealden of Surrey. Bulletin-Natural History Museum Geology Series 53, 11-70 (1997).

27. Colbert, E. H. The triassic dinosaur Coelophysis. (Museum of Northern Arizona, 1989).

28. Rauhut, O. W. M. The interrelationships and evolution of basal theropods (Dinosauria, Saurischia). Palaeontology 69, 1-215 (2003).

29. Rauhut, O. W. Osteology and relationships of a new theropod dinosaur from the Middle Jurassic of Patagonia. Palaeontology 48, 87-110 (2005).

30. Britt, B. Theropods of Dry Mesa Quarry (Morrison Formation, late Jurassic), Colorado, with emphasis on the osteology of Torvosaurus tanneri. Brigham Young University Geology. Studies 37, 1-72 (1991).

31. Gauthier, J. Saurischian monophyly and the origin of birds. Memoirs of the California Academy of sciences 8, 1-55 (1986).

32. Britt, B. B. Pneumatic postcranial bones in dinosaurs and other archosaurs, University of Calgary, Alberta, (1993).

33. Madsen, J. Jr. \& Welles, S. Ceratosaurus (Dinosauria, Theropoda). A revised osteology. Utah Geological Survey. Miscellaneous Publications 2, 1-80 (2000).

34. Stovall, J. W. \& Langston, W. Acrocanthosaurus atokensis, a new genus and species of Lower Cretaceous Theropoda from Oklahoma. The American Midland Naturalist 43, 696-728 (1950).

35. Benson, R. B. J., Butler, R. J., Carrano, M. T. \& Oconnor, P. M. Air-filled postcranial bones in theropod dinosaurs: physiological implications and the 'reptile'-bird transition. Biological Reviews 87, 168-193 (2012).

36. Allain, R. R. de Streptospondylus altdorfensis, le dinosaure théropode de Cuvier, du Jurassique de Normandie. Geodiversitas 23, 349-367 (2001).

37. Benson, R. B. J. A description of Megalosaurus bucklandii (Dinosauria: Theropoda) from the Bathonian of the UK and the relationships of Middle Jurassic theropods. Zoological Journal of the Linnean Society 158, 882-935 (2010).

38. Rauhut, O. W. M. The interrelationships and evolution of basal theropod dinosaurs. Palaeontology 69, 1-215 (2003).

39. Rauhut, O. W. \& Xu, X. The small theropod dinosaurs Tugulusaurus and Phaedrolosaurus from the Early Cretaceous of Xinjiang, China. Journal of Vertebrate Paleontology 25, 107-118 (2005).

40. Rauhut, O. W., Hübner, T. \& Lanser, K.-P. A new megalosaurid theropod dinosaur from the late Middle Jurassic (Callovian) of north-western Germany: Implications for theropod evolution and faunal turnover in the Jurassic. Palaeontologia Electronica 19, $1-65$ (2016).

41. Goloboff, P. A., Farris, J. S. \& Nixon, K. C. TNT, a free program for phylogenetic analysis. Cladistics 24, 774-786 (2008).

\section{Acknowledgements}

We thank Wei Guangbiao and He Jianjun for coordinating the fieldwork in Yunyang, Han Xiangsong for collecting the specimen, Zhang Yuqing for preparing the specimen. This work is supported by Natural Science Foundation of Chongqing, China (No. cstc2018jcyjAX0435), Postdoctoral Project of Chongqing, China (No. Xm2017069) and Project of Dinosaur Fossil Protection and Research of Chongqing Planning and Natural Resources Bureau (No. kj-2018035). X.X is supported by the National Natural Science Foundation of China (Grant No. 41688103). 


\section{Author contributions}

Hui Dai, Xing Xu and Roger Benson wrote the main manuscript text. Qingyu Ma, Shan Jiang, Deliang Li and Guangzhao Peng revised and improved the manuscript. Hui Dai, Qingyu Ma, Haiqian Hu and Yuxuan Zhou prepared all figures. Xufeng Hu, Chao Tan, Ming Xiao, Feng Zhang and Yilun Yu oversaw the project. Ning Li and Zhaoying Wei assisted with the measurement of the specimens and the writing of the manuscript. Yilun Yu helped to revise the phylogenetic tree. All authors reviewed the manuscript.

\section{Competing interests}

The authors declare no competing interests.

\section{Additional information}

Supplementary information is available for this paper at https://doi.org/10.1038/s41598-019-56959-x.

Correspondence and requests for materials should be addressed to H.D. or X.X.

Reprints and permissions information is available at www.nature.com/reprints.

Publisher's note Springer Nature remains neutral with regard to jurisdictional claims in published maps and institutional affiliations.

(c) (i) Open Access This article is licensed under a Creative Commons Attribution 4.0 International License, which permits use, sharing, adaptation, distribution and reproduction in any medium or format, as long as you give appropriate credit to the original author(s) and the source, provide a link to the Creative Commons license, and indicate if changes were made. The images or other third party material in this article are included in the article's Creative Commons license, unless indicated otherwise in a credit line to the material. If material is not included in the article's Creative Commons license and your intended use is not permitted by statutory regulation or exceeds the permitted use, you will need to obtain permission directly from the copyright holder. To view a copy of this license, visit http://creativecommons.org/licenses/by/4.0/.

(C) The Author(s) 2020 